\title{
Remarkable improvement and weight reduction in obese diabetic patient by continuation of super low carbohydrate diet (LCD)
}

\begin{abstract}
The case was 39-year old female patient with T2DM (BMI 33.3). She had a strong hope to receive Laparoscopic sleeve gastrectomy (LSG), but she could not take the operation of LSG because of severe diabetic control (HbA1c 11.4\%). She was treated with 5 kinds of diabetic medicine such as, Exenatide, Alogliptin, Metformin, Mitiglinide and Miglitol. She continued LCD successfully, with the improvement of HbA1c $10.8 \%$ to $6.3 \%$ and weight reduction $83.2 \mathrm{~kg}$ to $66.6 \mathrm{~kg}$. At 7 months, medicine was only Metformin. In our activity of Japan LCD Promotion Association (JLCDPA), super-LCD has been effective with 12\% of carbohydrate.
\end{abstract}

Keywords: non-communicable diseases, calorie restriction, super low carbohydrate diet, laparoscopic sleeve gastrectomy, Japan LCD promotion association
Volume 10 Issue 2 - 2020

\author{
Hiroshi Bando 1,2 \\ 'Tokushima University, Japan \\ 2Japan Low Carbohydrate Diet Promotion Association, Japan
}

Correspondence: Hiroshi Bando, Tokushima University / Medical Research, Nakashowa I-6I,Tokushima 770-0943, Japan, Tel+8I-90-3|87-2485, Email pianomed@bronze.ocn.ne.jp

Received: April 17, 2020 | Published: April 30, 2020
Abbreviations: NCD, non-communicable diseases; CR, calorie restriction; LCD, low carbohydrate diet; LSG, laparoscopic sleeve gastrectomy; JLCDPA, Japan LCD promotion association; ESG, endoscopic sleeve gastroplasty

\section{Introduction}

Across the world, the prevalence of obesity has been growing in the public health area including children, adolescents and adults. ${ }^{.}$The population with obese or overweight would be about $33 \% .^{1}$ This trend also brings a variety of concerns due to high mortality and comorbidity in obese people and influence to medical and economic burden for each country. ${ }^{2}$ As the prevalence of obesity and overweight becomes more, non-communicable diseases (NCDs) has been increasing more including diabetes mellitus, hypertension, dyslipidemia and arteriosclerotic diseases. ${ }^{3}$ They may bring several influences on medical, social and economic region. ${ }^{4}$ Diabetes mellitus cause chronic complications including macroangiopathy and microangiopathy. For the fundamental therapy for diabetes, nutritional treatment has been emphasized for long years by Calorie Restriction (CR), Low Carbohydrate Diet (LCD), and other types of regimen. ${ }^{5}$

Regarding nutritional treatment for obesity and diabetes, there has been a trend from CR to LCD. Lots of reports with comparison of these were found. ${ }^{6}$ Bernstein and Atkins had previously initiated LCD in the fields of medical and health area. ${ }^{7}$ After that, the predominance effect of LCD was observed in North American and European area. ${ }^{5,8}$ On the other hand, authors et al. have started LCD at first in Japan in 2000 s. ${ }^{9}$ After that, we have continued clinical practice and reported a variety of research. They include glucose daily glucose profile, comparison of $\mathrm{CR}$ and $\mathrm{LCD}$, ketone bodies $(\mathrm{KB})$, meal tolerance test (MTT), continuous glucose monitoring (CGM), physiological role of $\mathrm{KB}$ in the axis of newborn, mother, placenta and fetus. ${ }^{10,11}$ LCD seems to show stronger weight reducing effect for patients with obesity and diabetes in comparison with CR. ${ }^{12}$ There have been other treatments for reducing weight, which are surgery procedures. They include Endoscopic Sleeve Gastroplasty (ESG), Laparoscopic Sleeve Gastrectomy (LSG), Laparoscopic Band for Weight Loss, and so on. ${ }^{13}$ LSG has been rather known for its simple and higher efficacy. ${ }^{14}$ These operations have been increased worldwide, as patients with extreme obesity increase.

We have treated various patients with obesity so far. Among them, an obese female patient hoped to receive LSG, but could not have the operation because of severe diabetes. Then, we could successfully treat her with LCD. In this article, her general progress course and some discussion would be described.

\section{Case presentation}

Present history: The case was 39-year old female patient with T2DM. She had unremarkable diseases until 24 years old. Her body weight was around $54 \mathrm{~kg}$ until 28 years old. After marriage, her body weight had gradually increased up to $70 \mathrm{~kg}$. At 33 years old, she was pointed out to have T2DM, and started to receive oral hyperglycemic agents (OHA). However, her glucose variability had not improved, then she had been on several medicine for diabetes from 36 years old.As her body weight had been increased further, she became to hope reducing the weight by the surgery procedure. The patient had a strong hope to receive Laparoscopic sleeve gastrectomy (LSG). She often visited the surgery clinic in Tokyo, but she could not take the operation of LSG. Some reasons included i) her BMI was 33.3, which was lower than 35.0, ii) diabetic condition was too bad to be tolerated for the operation. Consequently, she was introduced to our diabetes clinic for further evaluation and treatment.

Physicals: Her physicals were evaluated in detail. She had normal consciousness and vitals including pulse, blood pressure, respiration, body temperature. There were no remarkable changes in the lung, heart and abdomen. She showed slight peripheral neuropathy in the hands and feet, no apparent retinopathy or nephropathy. Furthermore, there were no signs or symptoms related to hyper- or hypoglycemia. She has moderate obesity, with the body mass index (BMI) of 33.3 $\mathrm{kg} / \mathrm{m}^{2}$.

Laboratory exam: The data of the laboratory tests in complete blood count $(\mathrm{CBC})$ and biochemical data were revealed as follows: WBC $6200 / \mu \mathrm{L}, \mathrm{RBC} 4.16 \times 10^{6} / \mu \mathrm{L}, \mathrm{Hb} 13.3 \mathrm{~g} / \mathrm{dL}, \mathrm{Plt} 19.4 \times 10^{4} / \mu \mathrm{L}, \mathrm{AST}$ $25 \mathrm{IU} / \mathrm{mL}$, ALT $35 \mathrm{IU} / \mathrm{mL}$, ALP $202 \mathrm{IU} / \mathrm{mL}$ (100-340), LD $164 \mathrm{IU} /$ 
$\mathrm{mL}$ (100-210), T-Bil $0.6 \mathrm{mg} / \mathrm{dL}$, BUN $15 \mathrm{mg} / \mathrm{dL}$, Cre $0.7 \mathrm{mg} / \mathrm{dL}$, Uric Acid 5.2mg/dL, Na 142mmol/L, K $4.1 \mathrm{mmol} / \mathrm{L}, \mathrm{Cl} 102 \mathrm{mmol} / \mathrm{L}$, HDL $64 \mathrm{mg} / \mathrm{dL}, \mathrm{LDL} 151 \mathrm{mg} / \mathrm{dL}$, TG $207 \mathrm{mg} / \mathrm{dL}$. Data related diabetes were $\mathrm{HbA} 1 \mathrm{c} 11.8 \%$ and post-prandial blood glucose $356 \mathrm{mg} / \mathrm{dL}$.

\section{Clinical progress}

Before our visit, the patient showed high $\mathrm{HbAlc}$ value as $11-12 \%$ for months. At that time, she was treated with 5 kinds of medicine for diabetes. They included GLP-1 receptor agonist (Exenatide, 2mg/ week, D04121), DPP4-inhibitor (Alogliptin 25mg /day, D06553), Metformin $1000 \mathrm{mg} /$ day, Mitiglinide calcium hydrate $30 \mathrm{mg} /$ day and Miglitol $150 \mathrm{mg} /$ day. After our visit, we have explained the patient the significance and method of super-LCD (12\% of carbohydrate). She understood well and started and continued super-LCD for long months. Consequently, her $\mathrm{HbA} 1 \mathrm{c}$ decreased from $10.8 \%$ to $6.3 \%$, and body weight also decreased from $83.2 \mathrm{~kg}$ to $66.6 \mathrm{~kg}$ for 7 months (Figure 1). This clinical course was satisfactory in the light of diabetes and obesity. She did not have to consider the operation of LSG. At 7 months, she had on only Metformin $500 \mathrm{mg} /$ day as the prescription.

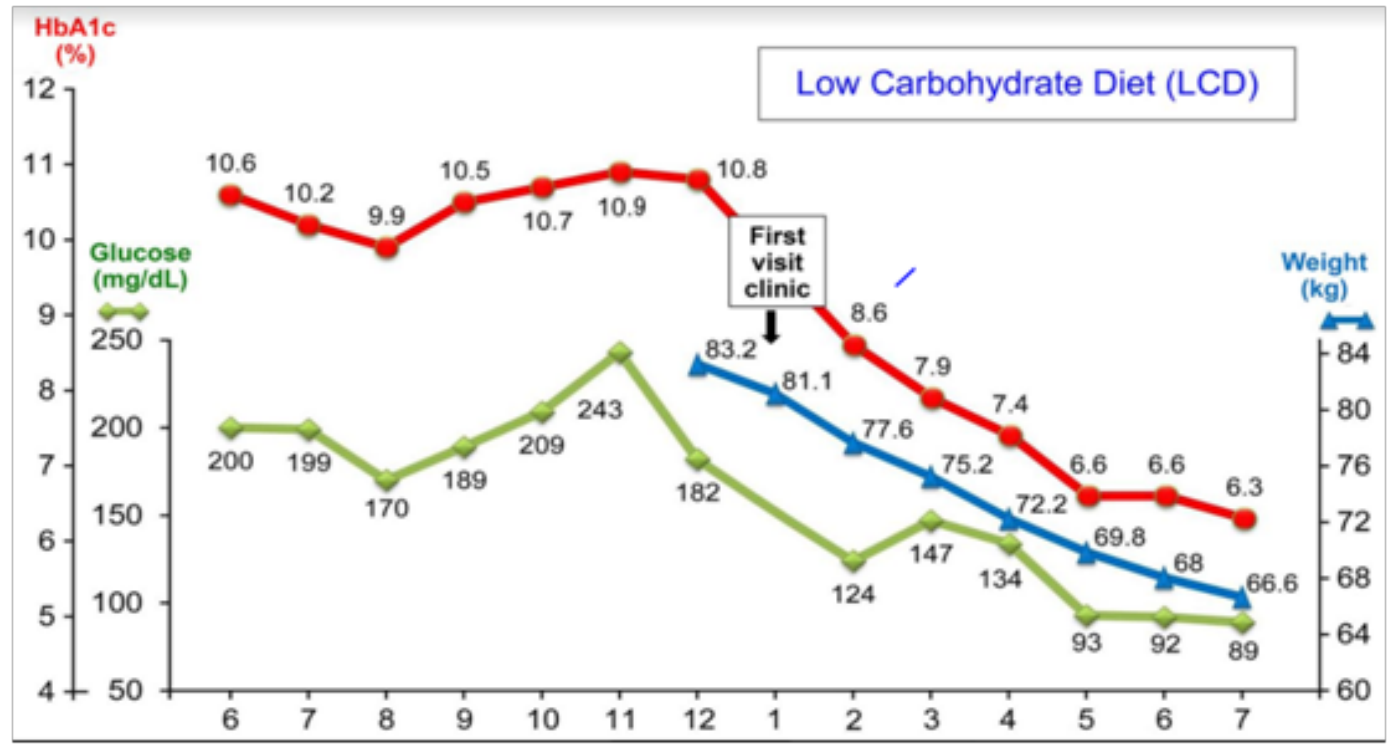

Figure I Clinical course of the case with $\mathrm{HbAIc}$, blood glucose and body weight.

\section{Discussion}

Authors and colleagues have begun LCD in Japan and developed LCD in medical and social area. We established Japan LCD Promotion Association (JLCDPA), and continued various activities. They include English papers, books about how to continue LCD, lectures for LCD, cooking workshops for LCD, and so on..$^{15}$ There are many divisions of JLCDPA in Japan so far, and we developed anti-aging movement with LCD, adequate exercise and ordinary life style habit. ${ }^{16}$ In order to propose a simple and easy to understand protocol of $\mathrm{LCD}$, we have proposed three types of LCDs. They are petite-LCD, standard-LCD and super-LCD. Those LCDs have the ratio of carbohydrate by calorie measurement a day as $40 \%, 26 \%$ and $12 \% .{ }^{17}$ In the case of superLCD with $1400 \mathrm{kcal} /$ day, the carbohydrate is $168 \mathrm{kcal} /$ day, because including $12 \%$ of carbohydrate. The calorie $168 \mathrm{kcal}$ of carbohydrate (4 kcal/g) means taking $42 \mathrm{~g}$ of carbohydrate a day. Consequently, super-LCD generally means the limited intake of carbohydrate about $42 \mathrm{~g}$ a day. When super-LCD is provided to diabetic patient with remarkable high glucose profile, glucose variability will be drastically improved within 2 days. ${ }^{17}$

LSG has been well-known restrictive bariatric surgical procedure for the surgery of the obesity. The reason would be from rather simple technique, satisfactory effect for weight loss and reduced morbidities. ${ }^{14}$ There was a comparison study of surgical interventions between LSG and Endoscopic Sleeve Gastroplasty (ESG) by cohort study.$^{13} \mathrm{As}$ a result, LSG showed greater reduction of BMI and percent total body weight loss (\%TBWL) than those of ESG at 12 months $\left(29.3 \%\right.$ vs $17.6 \%$, significant difference).$^{18}$

For LSG, systematic review of 27 relevant articles with 5218 cases were studied. ${ }^{19}$ It showed as follows: mean age was 41.1 years old, BMI decreased from $43.8 \pm 8.0$ to $30.7 \pm 3.9$ (1 year), remission rate of diabetes, hypertension and dyslipidemia was $81.9 \%, 66.5 \%$ and $64.1 \%$, respectively. ${ }^{19}$ These results show the efficacy of LSG. Quality of Life (QOL) after the operation of LSG were investigated. ${ }^{20}$ From 702 reports, 13 articles with 1630 cases in total were analyzed. Six kinds of QoL assessment tools were used. As a result, SF-36 revealed significant improvement between pre- and post-operative assessment. From BAROS score, $77-96 \%$ of cases evaluated achieving "good" to "excellent" outcomes. ${ }^{20}$

Historically speaking, there were different dietary approaches for diabetes and obesity. They include CR, Mediterranean, vegetarian, moderate carbohydrate, LCD, high-protein, low glycemic index/ glycemic load (GI/GL) and others. ${ }^{21}$ According to the comment of on American Diabetes Association (ADA) and European Association for the Study of Diabetes (EASD), LCDs have been recommended for the treatment of diabetic patients. ${ }^{22} \mathrm{LCD}$ has been defined as the meal with carbohydrate less than $26 \%$ of total daily energy intake. LCD has been known to have beneficial effect for improving glucose variability in diabetic patients. In contrast, there was no additional effect in the case of moderate restriction (26-45\%) of carbohydrate. ${ }^{22,23}$

In our previous report, we investigated 2699 cases of obesity with the treatment of LCD. ${ }^{24} \mathrm{As}$ a result, the patient ratio of weight reduction more than $10 \%$ was $25.6 \%$, and those more than $5 \%$ was $57.6 \%$. This clinical achievement would be satisfactory by LCD. ${ }^{24}$ The energy proportion of carbohydrate intake in a day would be furthermore studied including several factors such as longer term, countries and nutritional recommendations. ${ }^{25}$ In summary, a female patient withT2DM case was described. Her characteristic points include trying to receive LSG, successful LCD continuation and remarkable effects for $\mathrm{HbAlc}$ and weight reduction. Hopefully this information will be reference data for future clinical diabetic research. 


\section{Acknowledgments}

None.

\section{Conflicts of interest}

Author declare that there is no conflict of interest.

\section{Funding}

None.

\section{References}

1. Forse RA, Betancourt-Garcia MM, Kissee MC. Epidemiology and Discrimination in Obesity. In: Nguyen N, Brethauer S, Morton J, editors. The ASMBS Textbook of Bariatric Surgery. Springer, Cham. 2020.

2. Wu WC, Lee WJ, Yeh C, et al. Impacts of Different Modes of Bariatric Surgery on Plasma Levels of Hepassocin in Patients with Diabetes Mellitus. Reports. 2019;2:24.

3. Mauricio D, Alonso N, Gratacòs M. Chronic Diabetes Complications: The Need to Move beyond Classical Concepts. Trends in Endocrinology \& Metabolism. 2020

4. American Diabetes Association. Diabetes technology: Standards of Medical Care in Diabetesd. Diabetes Care. 2019;42(Suppl 1):S71-S80.

5. Feinman RD, Pogozelski WK, Astrup A, et al. Dietary carbohydrate restriction as the first approach in diabetes management: Critical review and evidence base. Nutrition. 2015;31(1):1-13.

6. Shai I, Schwarzfuchs D, Henkin Y, et al. Dietary Intervention Randomized Controlled Trial (DIRECT) Group. Weight Loss with a Low-Carbohydrate, Mediterranean, or Low-Fat Diet. $N$ Engl J Med. 2008;359:229-241.

7. Bernstein RK. Bernstein's Diabetes Solution. Little, Brown and company, New York; 1997.

8. Tay J, Thompson CH, Luscombe-Marsh ND, et al. Effects of an energyrestricted low carbohydrate, high unsaturated fat/low saturated fat diet versus a high-carbohydrate, low-fat diet in type 2 diabetes: A 2-year randomized clinical trial. Diabetes Obes Metab. 2018;20:858-871.

9. Bando H, Ebe K, Muneta T, et al. Effect of low carbohydrate diet on type 2 diabetic patients and usefulness of M-value. Diabetes Res Open J. 2017;3(1):9-16.

10. Muneta T, Kagaguchi E, Nagai Y, et al. Ketone body elevation in placenta, umbilical cord, newborn and mother in normal delivery. Glycat Stress Res. 2016;3(3):133-140.
11. Nakamura T, Bando H, Kawashima T, et al. Weight Reduction by Effective Protocol of Diet and Exercise. J Diab Obes Metab. 2020;2(1):106.

12. Novikov AA, Afaneh C, Saumoy M, et al. Endoscopic Sleeve Gastroplasty, Laparoscopic Sleeve Gastrectomy, and Laparoscopic Band for Weight Loss: How Do They Compare? J Gastrointest Surg. 2019;22:267-273.

13. Benaiges D, Más-Lorenzo A, Goday A, et al. Laparoscopic sleeve gastrectomy: More than a restrictive bariatric surgery procedure? World $J$ Gastroenterol. 2015;21:11804-11814.

14. Ebe $\mathrm{K}$, Bando H, Yamamoto K, et al. Daily carbohydrate intake correlates with HbAlc in low carbohydrate diet (LCD). J Diabetol. 2018;1(1):4-9.

15. Nakamura T, Kawashima T, Dobashi M, et al. Effective Nutritional Guidance for Obesity by Low Carbohydrate Diet (LCD). Asp Biomed Clin Case Rep. 20192(s1):16-21.

16. Bando H, Ebe K, Muneta T, et al. Clinical Effect of Low Carbohydrate Diet (LCD): Case Report. Diabetes Case Rep. 2017;2:124.

17. Wang JW, Chen CY. Current status of endoscopic sleeve gastroplasty: An opinion review. World journal of gastroenterology. 2020;26(11):11071112

18. Emile SH, Elfeki H, Elalfy K, et al. Laparoscopic Sleeve Gastrectomy Then and Now. Surgical Laparoscopy, Endoscopy \& Percutaneous Techniques. 2017;27(5):307-317.

19. Wityk M, Makarewicz W, Kaczmarkiewicz C, et al. Quality of life after laparoscopic sleeve gastrectomy - review of literature. Eur J Transl Clin Med. 2019;2(2):52-60.

20. Schwingshack1 L, Chaimani A, Hoffmann G, et al. Impact of different dietary approaches on glycemic control and cardiovascular risk factors in patients with type 2 diabetes: a protocol for a systematic review and network meta-analysis. Syst Rev. 2017;6(1):57.

21. Davies MJ, D’Alessio DA, Fradkin J, et al. Management of hyperglycemia in type 2 diabetes, 2018. A consensus report by the American Diabetes Association (ADA) and the European Association for the study of diabetes (EASD). Diabetes Care. 2018;41:2669-2701.

22. Slomski A. Low-Carb Diets Help Maintain Weight Loss. Clinical Trials Update. JAMA. 2019;321(4):335.

23. Bando H, Ebe K, Nakamura T, et al. Low Carbohydrate Diet (LCD): Long and short-term effects and hyperketonemia. Glycative Stress Research. 2016;3(4):193-204.

24. Korsmo-Haugen H-K, Brurberg KG, Mann J, et al. Carbohydrate quantity in the dietary management of type 2 diabetes: A systematic review and metaanalysis. Diabetes Obes Metab. 2019;21:15-27. 